Original Article

\title{
Frequency of Raised Urinary Trypsinogen-2 in Acute Pancreatitis
}

Mansab Ali ${ }^{1}$, Syed Mehsam ${ }^{1}$, Adeel Hussain ${ }^{1}$, Shahid Rasul $^{1}$, Sughra Parveen
Ahson Memon

1. Jinnah Postgraduate Medical Centre, Karachi Pakistan

2. Tabba Heart Institute

3. LUMHS, Hyderabad

Corresponding Author adeelhussain80@ hotmail.com

\section{Abstract}

Objectives To determine the frequency of raised Urinary Trypsinogen-2 in diagnosed patients of acute pancreatitis. Methodology Settings Patients in emergency refer to General Surgery ward-3 Jinnah Post Graduate and Medical Centre Karachi. Duration Six months, started from 20-01-2012 to 19-07-2012. Study Design Cross sectional descriptive study. Subjects and Methods All cases of Acute Pancreatitis diagnosed by Upper Abdominal Pain, Raised Serum Amylase and/or Serum Lipase and Abdominal CT Scan findings, were included in the study. Urinary Trypsinogen-2 dipstick test was done. All patient related data including age, gender, sex and raised Urinary Trypsinogen-2 or normal, was recorded. Data analysis was done on SPSS version 10. Frequency and percentage was calculated for gender and raised trypsinogen-2. Age and gender wise stratification was done to see the effect of these variables on outcome. Results Mean age of the patients was $38.14 \pm 7.42$ years. The minimum age was 24 years, while the maximum age was 63 years. Raised urinary trypsinogen-2 level was present in $55(65.5 \%)$ patients. Stratification of age group shows, that $40(66.7 \%)$ patients in age group $\leq 40$ years had raised urinary trypsinogen-2. Stratification of gender showed significant association with raised urinary trypsinogen-2 level (p-value 0.010). Conclusion The frequency of raised Urinary Trypsinogen-2 in diagnosed patients of acute pancreatitis was found to be high.

\section{Keywords}

Acute pancreatitis, Trypsinogen, Abdominal Pain, Serum Amylase, Serum Lipase

\section{Introduction}

Acute Pancreatitis is a common disorder observed in every part of the world ${ }^{1}$. The true incidence of AP remains controversial, and geographical, etiological, and diagnostic variations hinder accurate assessments. Studies have shown that in $12 \%$ to $42 \%$ of patients who die of AP, diagnosis occurs only at autopsy. Previous studies have shown a higher sensitivity along with a negative predictive values with a urine trypsinogen- 2 test ${ }^{2,3}$. The incidence of AP seems to increase in industrialized countries ${ }^{4,5}$. In Finland, where alcohol is the main cause of $\mathrm{AP}$, the increased incidence of AP was significantly correlated with the general increase in alcohol consumption between 1970 and $1989^{4}$.

Data on increased incidence should, however, be cautiously interpreted since the diagnostic criteria and methodology in the different studies vary widely. Therefore, better diagnostic procedures may also explain an increased incidence. As in a study conducted by Sáez ${ }^{6}$ he concluded 68\% frequency of raised urinary trysinogen- 2 in acute pancreatitis patients ${ }^{6}$. The aim of study was to find out the frequency of raised urinary trysinogen-2 in acute pancreatitis 
as no research work has been carried out in our Pakistan, and it is rapid (bed side) and cost effective in diagnosing acute pancreatitis. After doing this study, we would come to a point if we could use Urinary Trypsinogen-2 as a primary diagnostic test to initiate early management and decrease morbidity and mortality.

\section{Methodology}

A cross sectional study was conducted at General Surgery ward-3, Jinnah Post Graduate and Medical Centre Karachi January 2012 to July 2012 using Non-Probability Purposive sampling. Consent was taken from the patient to be included in the study. Urinary Trypsinogen-2 dipstick test was done on patients with upper abdominal pain, raised serum amylase and/or serum lipase and abdominal CT scan findings of acute pancreatitis (Diagnostic criteria 2010, Japan). While any congenital Gastro-intestinal tract abnormality, presence of short gut syndrome (past surgical history of bowel resection), pregnant women, peritonitis secondary to hollow viscus perforation and malabsorption syndrome were excluded from this study.

Trypsinogen-2 stick placed in urine sample of the patients (diagnosed as case of Acute Pancreatitis) was done for 5 minutes, when the color of the stick changed from White (normal) to Blue, they were labeled as having raised Urinary Trypsinogen-2 level. All patients' related data including age, gender, sex and raised Urinary Trypsinogen-2 level or normal level, was recorded.

Data analysis was done through statistical package for social sciences (SPSS-10.0). Ratio (M: F) was computed to present sex distribution. Age was presented by Mean + SD. Frequency and percentage was computed for frequency of raised urinary trypsinogen-2. Age and gender wise stratification was done to see the effect of these variables on it.

\section{Results}

Out of total 84 cases of Acute Pancreatitis mean age of the patients was $38.14 \pm 7.42$ years. Frequency of age group shows $60(71.4 \%)$ patients were present in age group $\leq 40$ years. Gender distribution shows 6.6 males per females.

Raised urinary trypsinogen-2 level was present in $55(65.5 \%)$ patients, while the rest of the patients 29 (34.5\%). (Figure 1) Stratification of age group shows that $40(66.7 \%)$ patients had raised urinary trypsinogen- 2 in the age group of $\leq 40$ years while, $15(62.5 \%)$ patients had raised urinary trypsinogen- 2 in the age group of $>40$ years (p-value 0.717). On stratification of gender, out of $73(86.9 \%)$ males, $44(60.3 \%)$ patients had raised urinary trypsinogen-2 level. On the other hand, all $11(100 \%)$ females had raised urinary trypsinogen-2 level (p-value 0.010). (Table 2)

\section{$65.50 \%$}

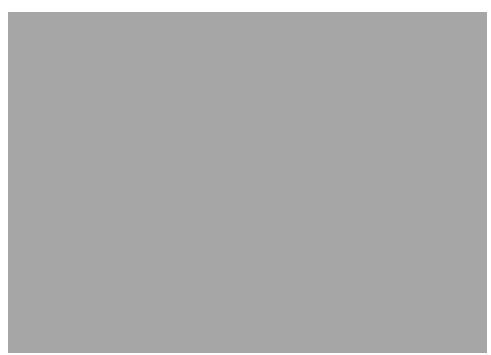

$34.50 \%$

Figure 1: Frequency of Urinary Trypsinogen-2

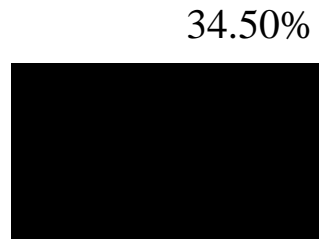




\begin{tabular}{|c|c|c|c|}
\hline \multicolumn{2}{|c|}{ Table 1: Comparison of urinary trypsinogen-2 with age and gender } \\
\hline \multirow{2}{*}{ Variables } & Urinary Trypsinogen-2 & \multirow{2}{*}{} \\
\cline { 2 - 3 } & Raised & Normal & \multirow{2}{*}{ p-value* } \\
\hline Age, years & $\mathrm{n}(\%)$ & $\mathrm{n}(\%)$ & \multirow{2}{*}{0.717} \\
\hline$\leq 40$ & $40(66.7)$ & $20(33.3)$ & \multirow{2}{*}{0.01} \\
\hline$>40$ & $15(62.5)$ & $9(37.5)$ & \multirow{2}{*}{0.01} \\
\hline Gender & $44(60.3)$ & $29(39.7)$ & \\
\hline Male & $11(100)$ & $0(0)$ & \multirow{2}{*}{} \\
\hline Female & $*$ Chi-square test applied \\
\hline
\end{tabular}

\section{Discussion}

Urinary Trypsinogen-2 dipstick test was done on patients with upper abdominal pain in our study. The most valuable clinical feature of the dipstick test was its ability to evaluate different cases regarding severe acute pancreatitis. It has been observed that Amylase concentrations come to the normal level within three to five days after the onset of acute pancreatitis ${ }^{7}$.

The sudden normalized values may indicate the resolution of the disease or extensive destruction of the pancreas, with the cessation of amylase production ${ }^{8}$. All patients with AP had urine trypsinogen-2 values above the upper reference limit ${ }^{9}$. Whereas, in our study, $55(65.5 \%)$ patients had raised urinary trypsinogen-2 level. Some patients with AP had extremely high concentrations of urine trypsinogen-2 (>100 000 ugfL). A possible explanation for the much greater increase of urinary trypsinogen-2 in AP is that the severe inflammatory reaction in combination with free proteolytic activity causes protein break-down and release of peptides. Because some amino acids are known to inhibit protein reabsorption in the renal tubules ${ }^{10}$, the tissue and protein breakdown occurring in pancreatitis could contribute to the very high urine concentrations of trypsinogen-2. The raised amylase clearance in AP found in the urine may be due to tubular insufficiency ${ }^{11}$.

Although the concentration of trypsinogen-2 in urine may be influenced by dehydration and impaired renal function, such effects are likely to be small in the early stages of pancreatitis $^{12}$. In spite of this potential limitation, trypsinogen- 2 in urine showed good accuracy for evaluation of the severity of the disease. As it is already known that serum trypsinogen- 2 is increased in dialysis patients $^{13}$, but the effect of moderately impaired renal function on urine trypsinogen-2 requires further study. Esko et $\mathrm{al}^{14}$ found that the concentration of trypsinogen- 2 remains elevated for 4 to 30 days in both urine and serum. In an experiment conducted by Mero et al. ${ }^{15}$, have depicted that total trypsinogen immunoreactivity level in serum may remain to be raised for nine days or above $\mathrm{e}^{15}$. These findings may help explain the high sensitivity of the trypsinogen-2 tests. The recent discovery of mutations in the trypsinogen-1 gene, presumably preventing the inactivation of trypsin-1, has led to the notion that trypsin-1 may be a key enzyme in the pathogenesis of AP, and that it is more important than trypsin- $2^{16}$. Under normal conditions the serum concentrations of trypsinogen-1 have been reported to be higher than those of trypsinogen- $2^{17}$, but 
only small amounts are recovered in urine ${ }^{18}$ by evaluating previous findings, it has been declared that during the phase of AP, the ratio is observed to be reversed and the concentrations evaluated for trypsinogen-2 are observed to be much greater than those of trypsinogen- $1^{7}$. Furthermore, in various studies it has been shown that the concentrations of trypsinogen- 2 correlates strongly with disease severity ${ }^{7,19,20}$.

In patients with AP, the serum concentrations of trypsinogen- 2 were found to be on an average 10-fold those of trypsinogen-1, and in urine the differences were even more striking (i.e. almost 14000fold). Furthermore, the serum concentrations of trypsinogen-2 remained elevated longer than did those of trypsinogen-1. This explains why trypsinogen- 2 is a more useful marker both for the diagnosis and severity assessment of AP in the typical clinical setting, where the time span between the induction of AP and arrival at the emergency department may be several days. It is probable that a drastic increase in the urine concentrations of trypsinogen- 2 is at least partially due to a disturbed reabsorption associated with a grossly increased excretion of protein fragments and peptides resulting from extensive tissue damage $^{20}$. Thus the urine levels would reflect not only the release of trypsinogen-2 from the pancreas, but also the degree of tissue damage in AP. This would explain the strong correlation with the severity of the disease.

\section{Conclusion}

The frequency of raised Urinary Trypsinogen-2 in patients of acute pancreatitis was found to be high.

\section{Conflict of Interest}

None

\section{Acknowledgement}

None

\section{References}

1. Steinberg, W., and Tenner, S. Acute pancre-atitis. N Engl J Med, 330(17), 1198-210, 1994.

2. Chien, N. H., Hung, C. S., Lee, C. L., \& $\mathrm{Wu}, \quad$ C. H. (2016). Rapid Urine Trypsinogen-2 Test for the Early Detection of Pancreatitis in Endoscopic Sphincterotomy Patients. JOP. Journal of the Pancreas.

3. Gurusamy, K. S., \& Davidson, B. R. (2015). Serum amylase and lipase and urinary trypsinogen and amylase for diagnosis of acute pancreatitis and serum C-reactive protein, procalcitonin and lactate dehydrogenase for the diagnosis of pancreatic necrosis. The Cochrane Library.

4. Jaakkola, M., \& Nordback, I. (1993). Pancreatitis in Finland between 1970 and 1989. Gut, 34(9), 1255-1260.

5. Lankisch, P. G., Schirren, C. A., Schmidt, H., Schönfelder, G., \& Creutzfeldt, W. (1989). Etiology and incidence of acute pancreatitis: a 20-year study in a single institution. Digestion, 44(1), 20-25.

6. Sáez, J., Martínez, J., Trigo, C., SánchezPayá, J., Laveda, R., Grino, P., García, C., \& Perez-Mateo, M. (2005). Clinical value of rapid urine trypsinogen-2 test strip, urinary trypsinogen activation peptide, and serum and urinary activation peptide of carboxypeptidase $B$ in acute pancreatitis. World journal of gastroenterology, 11(46), 7261-7265.

7. Itkonen, O., Koivunen, E., Hurme, M., Alfthan, H., Schroder, T., \& Stenman, U. H. (1990). Time-resolved immunofluorometric assays for trypsinogen-1 and 2 in serum reveal preferential elevation of trypsinogen- 2 in 
pancreatitis. J Lab Clin Med, 115(6), 712718.

8. Kemppainen, E. A., Hedström, J. I., Puolakkainen, P. A., Sainio, V. S., Haapiainen, R. K., Perhoniemi, V., Osman,S., Kivilaakso.E.O., \& Stenman, U. H. (1997). Rapid measurement of urinary trypsinogen-2 as a screening test for acute pancreatitis. New England journal of medicine, 336(25), 1788-1793.

9. Hedström, J., Sainio, V., Kemppainen, E., Puolakkainen, P., Haapiainen, R., Kivilaakso, E., Schauman,K.O., Stenman, U. H. (1996). Urine trypsinogen-2 as marker of acute pancreatitis. Clinical chemistry, 42(5), 685-690.

10. Johnson, S. G., Ellis, C. J., \& Levitt, M. D. (1976). Mechanism of increased renal clearance of amylase/creatinine in acute pancreatitis. New England Journal of Medicine, 295(22), 1214-1217.

11. Mogensen, C. E., \& Sølling, K. (1977). Studies on renal tubular protein reabsorption: partial and near complete inhibition by certain amino acids. Scandinavian journal of clinical and laboratory investigation, 37(6), 477-486.

12. Gudgeon, A. M., Hurley, P., Jehanli, A., Patel, G., Austen, B. M., Hermon-Taylor, J., Heath,D.I., Wilson,C., Shenkin,A.,\& Imrie, C. W. (1990). Trypsinogen activation peptides assay in the early prediction of severity of acute pancreatitis. The Lancet, 335(8680), 4-8.

13. Hedström, J., Leinonen, J., Sainio, V., \& Stenman, U. H. (1994). Time-resolved immunofluorometric assay of trypsin-2 complexed with alpha 1-antitrypsin in serum. Clinical chemistry, 40(9), 17611765.

14. Kemppainen, E. A., Hedström, J. I., Puolakkainen, P. A., Sainio, V. S., Haapiainen, R. K., Perhoniemi, V.,
Osman,S., Kivilaakso.E.O., \& Stenman, U. H. (1997). Rapid measurement of urinary trypsinogen-2 as a screening test for acute pancreatitis. New England journal of medicine, 336(25), 1788-1793.

15. Mero, M., Schröder, T., Tenhunen, R., \& Lempinen, M. (1982). Serum phospholipase A2, immunoreactive trypsin, and trypsin inhibitors during human acute pancreatitis. Scandinavian journal of gastroenterology, 17(3), 413416.

16. Whitcomb, D. C. (1999). Hereditary pancreatitis: new insights into acute and chronic pancreatitis. Gut, 45(3), 317-322.

17. Kimland, M., Russick, C., Marks, W. H., \& Borgström, A. (1989). Immunoreactive anionic and cationic trypsin in human serum. Clinica chimica acta, 184(1), 3146.

18. Borgström, A., \& Ohlsson, K. (1978). Studies on the turnover of endogenous cathodal trypsinogen in man. European journal of clinical investigation, 8(6), 379382.

19. Sainio, V., Puolakkainen, P., Kemppainen, E., Hedström, J., Haapiainen, R., Kivisaari, L. Stenman, H., Schoder.T., \& Kivilaakso, E. (1996). Serum trypsinogen-2 in the prediction of outcome in acute necrotizing pancreatitis. Scandinavian journal of gastroenterology, 31(8), 818-824.

20. Hedström, J., Haglund, C., Haapiainen, R., \& Stenman, U. H. (1996). Serum trypsinogen-2

and trypsin-2- $\alpha 1$-antitrypsin complex in malignant and benign digestive-tract diseases. Preferential elevation in patients with cholangiocarcinomas. International journal of cancer, 66(3), 326-331. 